\title{
Research on the Absence of Chinese Culture in University English Teaching
}

\author{
Li Yifei \\ Bohai University, Jinzhou, Liaoning, China, 121013 \\ liyifei163.com
}

Keywords: Chinese culture, university English teaching

\begin{abstract}
At present, the phenomenon of the absence of Chinese culture in university English teaching is very serious. Based on the description of this phenomenon, this paper analyses the necessity of the penetration of Chinese culture in university English teaching and gives three concrete strategies to accomplish it in order to provide some references to related researchers.
\end{abstract}

\section{Current Situation of the Absence of Chinese Culture in University English Teaching}

Language is the carrier of culture, and also an important part of culture. Therefore, since 1980s, university English teaching in China attaches great importance to the relationship between language and culture, emphasizing the cultivation of students' intercultural communicative competence. Nowadays, many university English teaching is no longer confined to a single language teaching. Teachers pay more attention to guide students to learn to express the carrying cultural cognition of the western culture on English, contributing to a better understanding of the world.

However, the output of Chinese culture is always in a weak position in the teaching of university English for a long time. Even in the cross-cultural communication, students can talk about American dream in English, it is difficult to introduce China dream in English, asked western people interested in Confucianism, is to make an ambiguous statement, look the other way. The students often give the concrete expression of the similar English and American cultural vocabulary but can one. For example, most of the students know Thanksgiving Day and Christmas, but only a handful of students know English translation of Chinese traditional festival of "Qingming Festival" and the "Duanwu Festival" is Tomb-Sweeping day and the Dragon Boat Festival. Most students know the White House, but only a handful of students know the Chinese palace is translated as the Imperial Palace. The vast majority of students know the Anglo American tradition food sandwich and pizza, but only a handful of students know the English translation of traditional Chinese food steamed bread and porridge. University English teaching has been basically get rid of the pure language teaching, culture teaching language very fruitful; but the need to attract attention, students in mastering certain western culture. At the same time, China culture has been severely neglected and college students lack the ability to express Chinese culture in English.

\section{Necessity of Penetration of Chinese Culture in University English Teaching}

\section{Need of Cultural Communication}

The purpose of learning English is to be able to communicate with others in English. The free-barrier communication is a two-way street. In the process of communication, we need not only to understand others, but also to show ourselves. To understand others, we need to understand the language and culture of other countries, not only to understand the meaning of the word itself, but also to understand the culture behind it contains; show themselves, we need to will have our own good culture in a foreign language accurate expression ability. If we know the culture of their own country to little or understanding does not reach the designated position, or even understanding in place, but cannot use English expression is accurate, will lead to the inefficiency and failure in cross cultural communication. In our daily teaching English, due to the lack of Chinese culture teaching, students generally suffer from "aphasia of Chinese culture". In future cross cultural communication, it is bound to produce a barrier to communication. Therefore, only we introduce Chinese culture in 
English teaching, can we improve the students' intercultural communication ability, and complete the communication and cooperation between different cultures.

\section{Need of Equal Dialogue}

In our daily English teaching, we tend to pay more attention to the British and American culture, and neglect the introduction of Chinese culture. Students in the English class and continue to contact the influence of British and American culture, they know Anglo American festivals, customs, celebrities and historical, and exposure to native culture understood, the passage of time is easy to produce the kind of this thought, resulting in in cross-cultural communication cannot equal dialogue. We should introduce Chinese culture in College English teaching, which makes the Chinese culture in the teaching of Chinese culture and American culture. At the same of the students learning the British and American culture, but also to learn to China five thousand years of splendid culture, resulting in a strong sense of national self-confidence and pride. In the process of cross-cultural communication, we should not only learn the advanced culture and technology, but also try to convey their own excellent culture and ideas. The introduction of Chinese culture in English learning can make the students understand and respect the basis of British and American culture and Chinese culture.

\section{Need of Comparison Learning}

To penetrate Chinese culture in university English teaching is not only the need of cultural communication and equal dialogue, but also the need of comparative learning. If students, if only to learn some of the customs, habits, some kind of festival, a certain religion in the study of British and American culture, it's difficult to understand and a solid grasp. Instead, if the teacher in the teaching process can be compared to American English culture and Chinese culture, let the students find the similarities and differences, cultivate students of Chinese and Western culture comparison and appreciation ability, the effect will be much better. As a teacher in the Christian spirit, teachers can compare them with the Chinese Confucian thought, so that students can master the two different culture characteristics and influence, more deeply understanding of the Christian spirit; for example, the teacher should teach students to learn the word "dragon" can compare it with China's "dragon". In Chinese, "dragon" often symbolizes the auspicious and noble, such as dragon and Phoenix, sons of the heaven. However, in the Anglo American culture, dragon is a symbol of evil forces to be a trend which cannot be halted. Through the introduction of Chinese culture to carry on the contrast study, the student understands English vocabulary and the Anglo and American culture. Therefore, the introduction of Chinese culture in university English teaching is also a need to comparison learning.

\section{Strategies of Penetration of Chinese Culture in University English Teaching}

\section{Optimize Textbook Complication}

Textbook is the basis of the teaching process, which plays a decisive role in the teaching process. We present the use of English textbooks, this paper choose English newspapers and magazines, and teaching is the vocabulary and grammar of English, the reflection is of Anglo American history and culture, for the excellent Chinese culture and history involves very little, and system. No input, no output, students with "China Culture Aphasia" is very common. The first thing we need to do is to optimize the preparation of teaching materials, and to import a large number of Chinese characteristic cultures. These pages need to be able to basically covering all aspects of Chinese culture, the content needs to be covering all aspects of ideas, medicine, martial arts, costumes, festivals, art, attractions, restaurants, drama, architecture, literature, and makes the students through learning materials, you can master the expression of most of the vocabulary related to culture with Chinese characteristics. These articles can be selected from the tunnel of the British and American newspapers. We can also invite senior experts to write. In addition, in the English textbooks can also show the classical Chinese literature, which can reflect the outstanding culture of our country already go out of the country, glory in the world, greatly enhance the students' sense of national pride. We want to pay attention to the organic combination of listening, speaking, reading, writing and translating teaching content.If it is equipped with corresponding audio and video, electronic 
books will increase vitality of teaching material, providing objective basis and reference for the teaching of Chinese culture.

\section{Change Education Ideas}

A very important reason that university English teachers seldom introduce the Chinese culture in the classroom teaching is that the first language has some obstacles in the target language learning. This argument is correct, but is not comprehensive. The deviation of teaching ideas also led to "an important reason China cultural aphasia". In teaching ideas, teachers of English mostly agree that "if you want to learn English well, we must understand the Anglo American culture" the idea, but in "to want to learn English well, must understand the Chinese culture" which exists serious differences. Many English teachers believe that the learning of the mother tongue culture has some inhibition effect on the target language learning. It should be said that this view has some rationality, but it also has certain error. The study of mother tongue culture can not only restrain the learning of target language, but also can play a great role in promoting. At present, however, many teachers teaching ideas stay in the culture of mother tongue learning of English learning plays an inhibitory role, in teaching, intentionally or unintentionally, to avoid Chinese culture teaching. This is also the "aphasia of Chinese culture" in teaching the lack of an important reason.Linguistic research shows that people always use the known things and experience to analyze the unknown world. In the language learning process, students always use native language naturally or half unconsciously learn foreign language. When the target language and the mother tongue are different in the grammar structure or vocabulary, the passive effect of learning the target language is called "the negative transformation". When they are the same in the grammar structure or vocabulary, we call the effect "positive transformation". Target language and native language are not at the same time in the grammar structure and vocabulary, and the mother tongue has a negative effect on the learning of target language ". The most common "negative transfer" is "Chinese style English". As a matter of fact, the teachers are worried that the negative transfer of mother tongue is exaggerated, and the positive transfer of mother tongue is ignored. Teachers should encourage students to use their mother tongue to learn a foreign language, try to play a positive role in the transfer of the mother tongue. In the learning process of target language, often can promote the learning of the mother tongue, the mother tongue and native culture plays an active role. Chinese traditional culture is very rich, to strive to explore." Teachers should change their teaching ideas, not because of the negative transfer of the mother tongue negative transfer of the mother tongue, and not in the classroom to introduce Chinese culture. In terms of the negative transformation of the mother tongue, the teacher should focus on the comparison between English and Chinese expression to prevent the occurrence of "Chinese style English".

\section{Reform Examination Regulations}

The lack of cultural examination in the university English examination system is another important reason for the "Chinese culture aphasia". Due to the current English exam much emphasis on vocabulary and grammar, students only need to memorize vocabulary and memorize grammar can get a high score, for the culture behind the language, especially Chinese culture will be indifferent. Indeed, most of the students are learning English in order to be able to pass the English test, four or six. Students spend a lot of energy to study. The students are indifferent to the content of the exam. The usual study, students need only memorizing the vocabulary, grammar, cloze, reading comprehension, as for the examination does not involve the "Confucius" in English how to say, "Dragon Boat Festival" in English how to say, don't care about. This test method for the exam is certainly effective, saving the students a lot of time, but when our students to take the exam, into the community to communicate with foreign guests, there will be an embarrassing phenomenon of culture of our country can't be expressed accurately. The reasons of examination system is also the cause of "one of the important reasons Chinese cultural aphasia".We should reform English examination system, reduce the English knowledge and skills of the inspection, examination of Chinese culture in English listening, speaking, reading, writing four skills increase the cultural aspects, especially, in order to mobilize the broad masses of teachers and students learning the enthusiasm of Chinese culture in English. University English four, six grade examination in the 
actual teaching is actually playing the role of baton. Four, six levels of tests add Chinese cultural knowledge test, inevitable meeting on College English teaching produced aftereffect, so as to form a complete unity and teaching. Take writing as an example in English four, six level, we can some similar to "write an essay up the significance of the Spring Festival" or "write an essay up the content of Chinese dream" essay in order to promote the students to express Chinese culture in English learning.

\section{Conclusion}

In summary, it is urgent to make China known by the world. Everyone is a messenger of transmitting Chinese culture to the world. No doubt that English--the most widely language is the medium to transmit our native culture. So we must incorporate Chinese culture into the current university English teaching, which is the necessity of the time and the communication.

\section{References}

[1] Liu Wenyang, Studies on the Absence of Chinese Culture inCollege English Teaching and the Countermeasures, J. Journal of Baicheng Normal University. 2014(4):109-112.

[2] Zhang Yan. On the Deficiency of Chinese Culture in College English Teaching, J. Overseas English. 2010(8): 101-103.

[3] Zhang Ni. A Cross-Cultural Perspective: An Integration of Traditional Chinese Culture into College English Textbooks, J. Overseas English. 2014(21): 38-39. 